\title{
An observational study to assess the drug prescription pattern and quality of life of acne vulgaris patients in a tertiary care center in India
}

\author{
Rohit M. Sane', Savita R. Shahani ${ }^{1}$, Aditya M. Sane ${ }^{2}$, Bandhavi Muppalla ${ }^{3 *}$
}

\author{
${ }^{1}$ Department of Pharmacology, MGM Medical College, Navi Mumbai, Maharashtra, India \\ ${ }^{2}$ Intern, Terna Medical College, Navi Mumbai, Maharashtra, India \\ ${ }^{3}$ Department of Dermatology, D. Y. Patil University School of Medicine, Navi Mumbai, Maharashtra, India
}

Received: 19 June 2020

Accepted: 31 July 2020

\section{*Correspondence:}

Dr. Bandhavi Muppalla,

Email: bandhavimuppalla@yahoo.com

Copyright: (C) the author(s), publisher and licensee Medip Academy. This is an open-access article distributed under the terms of the Creative Commons Attribution Non-Commercial License, which permits unrestricted non-commercial use, distribution, and reproduction in any medium, provided the original work is properly cited.

\begin{abstract}
Background: The study was conducted to assess the prescription pattern of acne vulgaris patients, and impact of antiacne treatment on severity of acne and change in quality of life (QoL) in patients.

Methods: A prospective observational study was conducted in dermatology OPD of a tertiary care hospital with 160 patients of acne vulgaris. All patients with acne vulgaris $>18$ years, of either sex were included while those with preexisting other cutaneous or systemic diseases, pregnant and lactating females and not giving consent were excluded from the study. Prescriptions were analysed and patients were followed-up at 2 and 6 weeks for assessment of change in acne severity and QoL, determined by GAGS score and CADI difference score, respectively.

Results: Mean age of patients was $20.7 \pm 2.5$ years, with males and females constituting $62(38.8 \%)$ and $98(61.3 \%)$ patients, respectively. Acne was mild in 88 (55\%), moderate in $51(31.9 \%)$ and severe in $21(13.1 \%)$ patients. A total of 537 drugs were prescribed to all patients, with an average of 3.36 drugs per prescription. Two, 3 and 4 drugs were prescribed in $2.5 \%, 59.4 \%$ and $38.1 \%$ patients, respectively. There was significant improvement in the GAGS score $(\mathrm{p}<0.001)$ and QoL (CADI score difference) $(\mathrm{p}<0.001)$ at 2 and 6 weeks follow-up compared to initial visit.

Conclusions: Polypharmacy was a common practice in anti-acne treatment. However, it was associated with improvement in acne severity and QoL.
\end{abstract}

Keywords: Anti-acne treatment, CADI, GAGS, Poly-pharmacy

\section{INTRODUCTION}

Acne vulgaris is a major cosmetic concern in adolescents and adults. The treatment include several options- 1) topical/oral retinoids, having comedo-mimetic and sebosuppressive and anti-inflammatory properties, 2) topical/ oral antibiotics, having anti-microbial action, 3) Benzoyl peroxide, having anti-inflammatory and comedolytic action, 4) hormonal agents, causing sebo-suppression. The American Academy of Dermatology (AAD 2016) have given treatment algorithms depending on the severity of acne vulgaris. Thus, the treatment approaches may be different in patients. ${ }^{1}$
Studies of drug use patterns, in a particular disease condition in a hospital setting, assists in analysing the rational use of drugs. ${ }^{2,3}$ Intermittent and regular audits are essential as they help to assess therapeutic efficacy, reduce occurrence of adverse effects and most importantly, provides feedback to prescribers to check, and monitor if the prescribing practices are in accordance with the standards of medical treatment as per the guidelines. ${ }^{3,4}$ This study was planned to assess the demographic pattern and drug utilization of acne vulgaris patients, and the impact of anti-acne medications on the severity of acne and quality of life (QoL). 


\section{METHODS}

This cross-sectional study was conducted in a Dermatology out-patient department settings of a tertiary care hospital in Navi Mumbai, India from April 2017 to March 2018.

\section{Inclusion criteria}

Patients, more than 18 years of either sex, with acne vulgaris seeking medical intervention for acne were included in the study following a written informed consent.

\section{Exclusion criteria}

Patients with co-existing other cutaneous or systemic diseases, pregnant and lactating females and not consenting for participation were excluded.

Permission of the Institutional Ethics Committee was obtained before commencement of the study (2017/03/SC/32). The demographic details, clinical history, examination findings, and drugs prescribed were recorded with the help of predesigned case record form. Severity of acne was judged according to the Global Acne Grading System (GAGS). ${ }^{5}$ QoL was assessed using a licensed version of Cardiff Acne Disability Index (CADI). ${ }^{6}$ The Hindi version of the questionnaire, which has been validated earlier, was used for patients who were not comfortable for CADI in English. ${ }^{7}$ Patients were followed up at 2 and 6 weeks of initial visit for assessing the change in severity and QoL. Subjective assessment of acne improvement was evaluated using visual analogue scale (VAS) at follow-up, wherein 0 and 10 indicated no improvement and complete improvement, respectively.

Data from the case record forms was entered in a Microsoft excel sheet and analysed using SPSS version 21 software. Descriptive statistics were assessed and represented as Mean+SD, frequencies and percentages. Quantitative data (which was not normally distributed) within the group at more than 2 intervals was compared using Friedman's test, with post hoc analysis using Wilcoxon signed rank test. The level of significance in the study was $<0.05$.

\section{RESULTS}

During the study period, 160 patients consented for participation. Demographics and other characteristics of the patients have been described in Table 1 .

Previous treatment for acne was taken by 35 (21.9\%), of which $9(5.6 \%)$ had taken oral medications while 26 $(16.3 \%)$ had taken topical treatment. Among these, 25 (71.4\%) reported cure for acne. Among the patients, severity of acne was mild in $88(55 \%)$, moderate in 51 $(31.9 \%)$, and severe in $21(13.1 \%)$.
Table 1: Demographic characteristics of all participants included in the study.

\begin{tabular}{|c|c|c|}
\hline Demographics & & Values \\
\hline Age (in years) & & $20.6 \pm 2.5$ \\
\hline \multirow{2}{*}{ Gender } & Males & $62(38.8 \%)$ \\
\hline & Females & $98(61.3 \%)$ \\
\hline \multirow{4}{*}{$\begin{array}{l}\text { Total duration of } \\
\text { history of acne }\end{array}$} & $<2$ months & $17(10.6 \%)$ \\
\hline & 3-6 months & $23(14.4 \%)$ \\
\hline & 6-12 months & $34(21.3 \%)$ \\
\hline & $>12$ months & $86(53.8 \%)$ \\
\hline \multirow{4}{*}{$\begin{array}{l}\text { Duration of } \\
\text { current acne } \\
\text { complaints }\end{array}$} & $<2$ months & $21(13.1 \%)$ \\
\hline & 3-6 months & $37(23.1 \%)$ \\
\hline & 6-12 months & $70(43.8 \%)$ \\
\hline & $>12$ months & $32(20 \%)$ \\
\hline \multirow{3}{*}{$\begin{array}{l}\text { Aggravating } \\
\text { factors* }\end{array}$} & Stress & $85(53.2 \%)$ \\
\hline & Seasonal variation & $55(34.4 \%)$ \\
\hline & Use of cosmetics & $10(6.3 \%)$ \\
\hline \multirow{2}{*}{$\begin{array}{l}\text { Associated } \\
\text { symptoms* }\end{array}$} & Seborrhoea & $54(33.8 \%)$ \\
\hline & Weight gain & $1(0.6 \%)$ \\
\hline \multirow{2}{*}{ Personal habits } & Smoking & $8(5 \%)$ \\
\hline & Alcohol consumption & $0(0 \%)$ \\
\hline \multirow{2}{*}{ Diet } & Vegetarian & $61(38.1 \%)$ \\
\hline & Non-vegetarian & $99(61.9 \%)$ \\
\hline \multirow{2}{*}{$\begin{array}{l}\text { Menstrual history } \\
\text { (in females) }\end{array}$} & Irregular & $1(1 \%)$ \\
\hline & Regular & $97(99 \%)$ \\
\hline \multirow{4}{*}{$\begin{array}{l}\text { Age of menarche } \\
\text { (in females) }\end{array}$} & 12 years & $22(22.4 \%)$ \\
\hline & 13 years & $47(48 \%)$ \\
\hline & 14 years & $28(28.6 \%)$ \\
\hline & 15 years & $1(1 \%)$ \\
\hline \multirow{2}{*}{$\begin{array}{l}\text { Frequency of } \\
\text { menstrual cycle (in } \\
\text { females) }\end{array}$} & 28-30 days & $91(92.9 \%)$ \\
\hline & $>45$ days & $7(7.1 \%)$ \\
\hline \multirow{3}{*}{$\begin{array}{l}\text { Duration of } \\
\text { menstruation (in } \\
\text { females) }\end{array}$} & 3-5 days & $45(45.9 \%)$ \\
\hline & 5 days & $38(38.8 \%)$ \\
\hline & $>5$ days & $15(15.3 \%)$ \\
\hline
\end{tabular}

*values are mutually exclusive of each other

\section{Prescription pattern analysis}

Numbers of drugs prescribed, anti-acne drugs were 2 in 4 $(2.5 \%), 3$ in $95(59.4 \%)$, and 4 in $61(38.1 \%)$, with an average of 3.36 drugs per prescription.

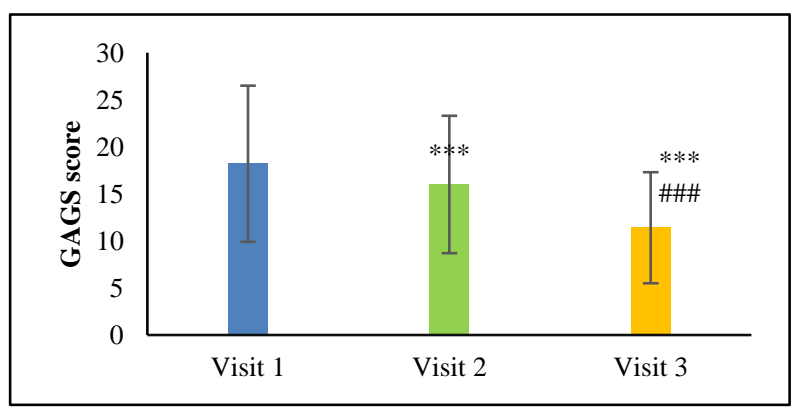

Figure 1: Change in severity of acne as assessed by GAGS.

Friedman's test, $* * * \mathrm{p}<0.001$ versus visit $1, \# \# \mathrm{p}<0.001$ versus visit 2 . 
Medications prescribed according to their severity of acne have been described in Table 2, 3 and 4 . Additionally, chemical peels were performed in $8(5 \%)$ patients. Drugs prescribed to the patients were in according with the AAD 2016 guidelines.
The severity of acne, as assessed by GAGS score, improved significantly $(\mathrm{p}<0.001)$ from $18.2 \pm 8.3$ at $1^{\text {st }}$ visit, to $16 \pm 7.3$ and $11.4 \pm 5.9$ at 2 and 6 weeks, respectively (Figure 1).

Table 2: Outline of medications prescribed to patients with mild acne in the study.

\begin{tabular}{|c|c|c|c|c|c|c|c|}
\hline Generic Name & Brand name & Dose & Drug route & $\begin{array}{l}\text { Frequency of } \\
\text { administration }\end{array}$ & $\begin{array}{l}\text { Duration } \\
\text { (in weeks) }\end{array}$ & $\begin{array}{l}\text { Number of } \\
\text { patients* }\end{array}$ & $\%($ of 88$) *$ \\
\hline $\begin{array}{l}\text { Adapalene+ } \\
\text { Clindamycin }\end{array}$ & $\begin{array}{l}\text { Deriva CMS } \\
\text { gel }\end{array}$ & $\begin{array}{l}0.1 \% \mathrm{w} / \mathrm{w}+ \\
1 \% \mathrm{w} / \mathrm{w}\end{array}$ & Topical & OD & 6 & 68 & 77.3 \\
\hline $\begin{array}{l}\text { Adapalene+ } \\
\text { Benzoyl peroxide }\end{array}$ & Minoz BPO gel & $\begin{array}{l}0.1 \% \mathrm{w} / \mathrm{w}+ \\
2.5 \% \mathrm{w} / \mathrm{w}\end{array}$ & Topical & OD & 6 & 22 & 25 \\
\hline Clindamycin & Clindac A gel & $1 \% \mathrm{w} / \mathrm{w}$ & Topical & OD & 6 & 5 & 5.7 \\
\hline $\begin{array}{l}\text { Clindamycin+ } \\
\text { Nicotinamide }\end{array}$ & Glocin gel & $\begin{array}{l}1 \% \mathrm{w} / \mathrm{w}+ \\
4 \% \mathrm{w} / \mathrm{w}\end{array}$ & Topical & OD & 6 & 54 & 61.4 \\
\hline Doxycycline & Doxy & $100 \mathrm{mg}$ & Oral & OD & 6 & 30 & 34.1 \\
\hline $\begin{array}{l}\text { Foaming } \\
\text { facewash }\end{array}$ & $\begin{array}{l}\text { Kimklin aha } \\
\text { facewash }\end{array}$ & - & Topical & & - & 1 & 1.1 \\
\hline $\begin{array}{l}\text { Salicylic acid+ } \\
\text { Glycolic acid }\end{array}$ & $\begin{array}{l}\text { Clindac A } \\
\text { facewash }\end{array}$ & - & Topical & $\begin{array}{l}\text { BD } \\
\text { OD }\end{array}$ & 6 & $\begin{array}{l}79 \\
2\end{array}$ & 92 \\
\hline
\end{tabular}

*values are mutually exclusive of each other.

Table 3: Outline of medications prescribed to patients with moderate acne in the study.

\begin{tabular}{|c|c|c|c|c|c|c|c|}
\hline Generic Name & Brand Name & Dose & Drug route & $\begin{array}{l}\text { Frequency of } \\
\text { administration }\end{array}$ & $\begin{array}{l}\text { Duration } \\
\text { (in weeks) }\end{array}$ & $\begin{array}{l}\text { Number of } \\
\text { patients* }\end{array}$ & $\%($ of 51$) *$ \\
\hline $\begin{array}{l}\text { Adapalene+ } \\
\text { Clindamycin }\end{array}$ & Deriva CMS gel & $\begin{array}{l}0.1 \% \mathrm{w} / \mathrm{w}+ \\
1 \% \mathrm{w} / \mathrm{w}\end{array}$ & Topical & OD & 6 & 51 & 100 \\
\hline Azithromycin & Azee & $500 \mathrm{mg}$ & Oral & OD & 6 & 7 & 13.7 \\
\hline Clindamycin & Clindac A gel & $1 \% \mathrm{w} / \mathrm{w}$ & Topical & OD & 6 & 30 & 58.8 \\
\hline $\begin{array}{l}\text { Clindamycin+ } \\
\text { Nicotinamide }\end{array}$ & Glocin gel & $\begin{array}{l}1 \% \mathrm{w} / \mathrm{w}+ \\
4 \% \mathrm{w} / \mathrm{w}\end{array}$ & Topical & OD & 6 & 19 & 37.2 \\
\hline Doxycycline & Doxy & $100 \mathrm{mg}$ & Oral & OD & 6 & 32 & 62.7 \\
\hline $\begin{array}{l}\text { Doxycycline+ } \\
\text { Lactobacillus }\end{array}$ & Doxy-bond LB & $100 \mathrm{mg}$ & Oral & OD & 6 & 11 & 21.6 \\
\hline $\begin{array}{l}\text { Foaming } \\
\text { facewash }\end{array}$ & $\begin{array}{l}\text { Kimklin aha } \\
\text { facewash }\end{array}$ & - & Topical & & - & 32 & 62.7 \\
\hline $\begin{array}{l}\text { Salicylic acid+ } \\
\text { Glycolic acid }\end{array}$ & $\begin{array}{l}\text { Clindac A } \\
\text { facewash }\end{array}$ & - & Topical & $\begin{array}{l}\text { OD } \\
\text { BD }\end{array}$ & 6 & $\begin{array}{l}3 \\
9 \\
\end{array}$ & 23.5 \\
\hline
\end{tabular}

*values are mutually exclusive of each other.

Table 4 Outline of medications prescribed to patients with severe acne in the study.

\begin{tabular}{|c|c|c|c|c|c|c|c|}
\hline Generic Name & Brand Name & Dose & $\begin{array}{l}\text { Drug } \\
\text { route }\end{array}$ & $\begin{array}{l}\text { Frequency of } \\
\text { administration }\end{array}$ & $\begin{array}{l}\text { Duration } \\
\text { (in weeks) }\end{array}$ & $\begin{array}{l}\text { Number of } \\
\text { patients * }\end{array}$ & $\%(\text { of } 21)^{*}$ \\
\hline $\begin{array}{l}\text { Adapalene+ } \\
\text { Clindamycin }\end{array}$ & Deriva CMS gel & $\begin{array}{l}0.1 \% \mathrm{w} / \mathrm{w}+ \\
1 \% \mathrm{w} / \mathrm{w}\end{array}$ & Topical & OD & 6 & 19 & 90.5 \\
\hline $\begin{array}{l}\text { Adapalene+ } \\
\text { Benzoyl peroxide }\end{array}$ & Minoz BPO gel & $\begin{array}{l}0.1 \% \mathrm{w} / \mathrm{w}+ \\
2.5 \% \mathrm{w} / \mathrm{w}\end{array}$ & Topical & OD & 6 & 2 & 9.5 \\
\hline Clindamycin & Clindac A gel & $1 \% \mathrm{w} / \mathrm{w}$ & Topical & $\begin{array}{l}\text { OD } \\
\text { BD }\end{array}$ & 6 & $\begin{array}{l}18 \\
1\end{array}$ & 90.5 \\
\hline $\begin{array}{l}\text { Clindamycin+ } \\
\text { Nicotinamide }\end{array}$ & Glocin gel & $\begin{array}{l}1 \% \mathrm{w} / \mathrm{w}+ \\
4 \% \mathrm{w} / \mathrm{w}\end{array}$ & Topical & OD & 6 & 1 & 4.8 \\
\hline Doxycycline & Doxy & $100 \mathrm{mg}$ & Oral & OD & 6 & 2 & 9.5 \\
\hline Isotretinoin & Isotret & $20 \mathrm{mg}$ & Oral & OD & $\begin{array}{l}60 \\
\text { days }\end{array}$ & 19 & 90.5 \\
\hline
\end{tabular}




\begin{tabular}{|llllllll|}
\hline Generic Name & Brand Name & Dose & $\begin{array}{l}\text { Drug } \\
\text { route }\end{array}$ & $\begin{array}{l}\text { Frequency of } \\
\text { administration }\end{array}$ & $\begin{array}{l}\text { Duration } \\
\text { (in weeks) }\end{array}$ & $\begin{array}{l}\text { Number of } \\
\text { patients * }\end{array}$ & \% (of 21)** \\
\hline $\begin{array}{l}\text { Foaming } \\
\text { facewash }\end{array}$ & $\begin{array}{l}\text { Kimklin aha } \\
\text { facewash }\end{array}$ & - & Topical & & - & 19 & 90.5 \\
\hline $\begin{array}{l}\text { Salicylic acid+ } \\
\text { Glycolic acid }\end{array}$ & $\begin{array}{l}\text { Clindac A } \\
\text { facewash }\end{array}$ & - & Topical & OD & 6 & 1 & 4.8 \\
\hline *values are mutually exclusive of each other. & & & & & \\
\hline
\end{tabular}

The VAS scores at 2 and 6 weeks were $5.9 \pm 1.3$ and $7.4 \pm 1.2$, respectively, indicating improvement in acne with treatment, as perceived by the patients.

The quality of life improved significantly $(\mathrm{p}<0.001)$, with improvement in CADI difference scores from 5.1 \pm 3.2 at $1^{\text {st }}$ visit to $4.5 \pm 2.9$ and $2.9 \pm 2.6$, at 2 and 6 weeks, respectively (Figure 2 ).

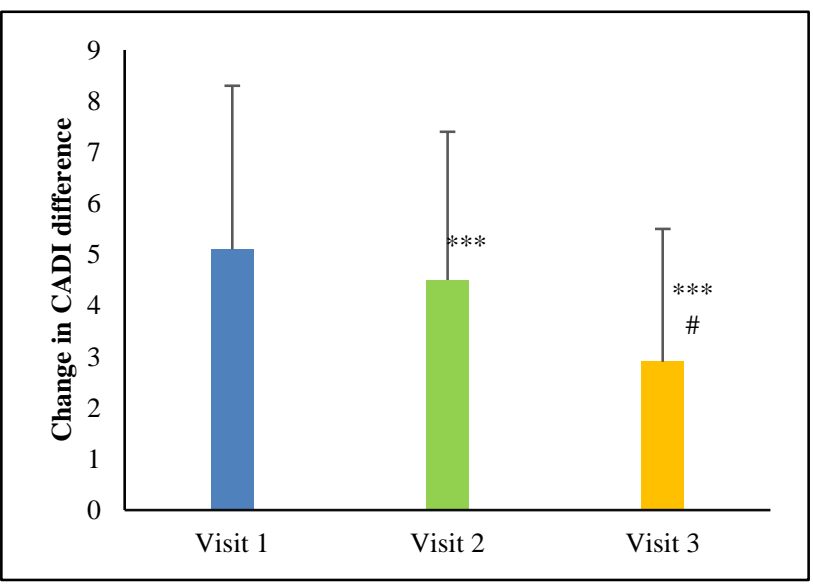

Figure 2: Improvement in quality of life as assessed by change in CADI.

Friedman's test, $* * * \mathrm{p}<0.001$ versus visit $1,{ }^{*} \mathrm{p}<0.05$ versus visit 2.

\section{DISCUSSION}

Prescription pattern is an important tool in determining the quality of patient care in a particular health care setting. Drug utilization studies assist to objectively evaluate the practices of health professionals and give them feedback regarding the same, in order to stimulate them to think over their practices. This helps to determine and encourage rational use of drugs in particular patient population. This study was carried out in an OPD setting in dermatology in a tertiary care hospital.

In present study, about $59.4 \%$ patients of acne vulgaris in the study had 3 drugs, with an average of 3.36 drugs per prescription. According to severity, among patients with mild acne, $77.3 \%$ received adapalene + clindamycin gel, $61.4 \%$ received clindamycin + nicotinamide gel, and $92 \%$ received salicyclic acid + glycolic acid facewash. Among patients with moderate acne, $100 \%$ received adapalene + clindamycin gel, $62.7 \%$ received oral doxycycline and foaming facewash, and $58.8 \%$ received clindamycin gel. Among patients with severe acne, $90.5 \%$ received adapalene + clindamycin gel, clindamycin gel, foaming facewash, and oral tablet of isotretinoin.

Different studies have reported different proportion of patients with varied severity of acne. In present study, acne was graded according to the Global Acne Grading System (GAGS). ${ }^{5}$ More than half $(55 \%)$ patients had mild acne, $31.9 \%$ had moderate acne, while $13.1 \%$ had severe acne. In this study, GAGS was used for classifying acne as it is a validated scale and most importantly, quantifies the measure of acne severity making it more objective in use. Most of the previous similar studies, have used acne grading suggested by Tutakne et al..$^{5}$ The authors agree that though the scale proposed by Tutakne et al is a simple grading system, it is a subjective scale depending on the assessor and does not take into consideration the lesions present all over the body. Moreover, its use may be confusing when mixed lesions are present. Various studies have segregated the severity of acne as grade 1, 2, 3 and $4 .^{8-12}$

In present study, 3.36 drugs per prescription were noted. The average number of medications per prescriptions by various studies are as follows- Kumar et al- 4.76, Patro et al- 3.003, Agarwal et al- 4.01 drugs, Kamerkar- 3.04, Nandini et al- 2.49, Gupta et al- 4.14, Chandani et al- 4.32 drugs, Pooja et al- 1.77 drugs. ${ }^{8-15}$ Thus, from all studies, it can be observed that multidrug therapy is a common practice in acne vulgaris patients.

In current study, all drugs to the acne vulgaris were prescribed by brand names. Similarly, use of brand names was reported as $100 \%$ by Kumar et al, $48 \%$ by Agarwal et al, $98.7 \%$ by Pooja et al study. ${ }^{12-14}$ In present study, monotherapy was not observed, with 2 drugs prescribed in $2.5 \%, 3$ drugs prescribed in $59.4 \%$, and 4 drugs prescribed in $38.1 \%$. Topical medications constituted $81.19 \%$ of all medications prescribed while $18.8 \%$ were oral medications. Thus, overall multidrug therapy and predominantly topical medications was a common practice in the current Institutional settings. Apart from drugs for acne vulgaris, no additional/concomitant medications were prescribed in the treatment. In Giri et al study, topical monotherapy was prescribed in $80 \%$ while topical polytherapy was prescribed in $20 \%$ patients, and systemic monotherapy was prescribed in $42.5 \%$ and polytherapy in $57.5 \% .^{16}$ In Kumar et al study, of all the total medicines $(n=1135)$, topical therapy was constituted $58.5 \%$ while oral therapy constituted $41.5 \%$ of all medicines. Among the topical drugs, $96.38 \%$ were single while $3.08 \%$ were combination medications, while among the oral drugs, $97.66 \%$ were single while $2.34 \%$ were 
combinations. ${ }^{13}$ In Patro et al study, among the total drugs prescribed, oral drugs constituted $47.44 \%$, while drugs given topical route constituted $52.26 \%$, with practice of monotherapy in $6.2 \%$ and polytherapy in $93.8 \% .^{8}$ In Agarwal et al study, in 1164 prescriptions, among oral drugs, single drug was prescribed in $36 \%$, two drugs in $53 \%$, and three drugs in $10.6 \%$, while among topical medications, single topical agent was used in $55 \%$, two drugs were used in $45 \%$, and three drugs were used in $0.5 \% .{ }^{14}$ In Nandini et al study, $15.24 \%$ prescriptions had single drug, $48.09 \%$ had 2 drugs, $25.71 \%$ had 3 drugs and $10.95 \%$ had $>4$ drugs. $^{9}$ In their study, $46.2 \%$ drugs were prescribed by oral route and $53.8 \%$ were by topical route. In Sharma et al study, topical monotherapy was prescribed in $81.76 \%$ patients, while topical polytherapy was practiced in $18.23 \% .{ }^{17}$ In Gupta et al study, $33 \%$ drugs were prescribed by oral route while $67 \%$ drugs were prescribed by topical route. ${ }^{10}$ In Chandani et al study, $69.92 \%$ drugs were topical and $30.07 \%$ drugs were oral. ${ }^{11}$ In Pooja et al study, $41 \%$ prescriptions had single drug, $42.2 \%$ had 2 drugs, $15.6 \%$ had 3 drugs and $1.2 \%$ had 4 drugs. In their study, $83.99 \%$ drugs were given for topical applications and $16.01 \%$ were given for use by systemic route. ${ }^{12}$ Thus, in almost all studies, the topical route was the most common. This might be due to use of topical medications in all the severity of acne while systemic use is generally limited to the higher grade of acne severity.

In Giri et al study, among topical medications given as monotherapy, $2.5 \%$ and $5 \%$ benzoyl peroxide was prescribed in $18.3 \%$ and $26.7 \%$ patients, respectively, $15.8 \%$ with clindamycin $1 \%, 9.2 \%$ with adapalene $0.05 \%$, and $5.8 \%$ with ketoconazole $10 \%$. Topical polytherapy medications used in their study were clindamycin phosphate $(1 \%)$, aloe vera $(10 \%)$, liquid paraffin $(7 \%)$, and white soft paraffin $(5 \%)$ in $20 \%$ patients. ${ }^{16}$ In Kumar et al study, among the single topical preparations, clindamycin was most common used in $30.87 \%$ followed by nicotinamide in $24.85 \%$, while among topical combinations, mometasone + miconazole was commonest in $86.36 \% .^{13}$ In Agarwal et al study, among the topical medications with monotherapy, clindamycin was most common in $28 \%$, followed by benzoyl peroxide in $12 \%$ and tretinoin in $10 \%$, while among those with polytherapy topical drugs, clindamycin + benzoyl peroxide was used in $25 \%$, followed by clindamycin + tretinoin in $13 \%$, with overall clindamycin being the most common topical agent. ${ }^{14}$ In Kamerkar study, among topical formulations, clindamycin was most common in $48.4 \%$ patients, followed by adapalene in $26.56 \%$, and salicylic acid in $15.6 \% .{ }^{15}$ In Nandini et al study, among the topical agents, clindamycin was commonest in $13.24 \%$, followed by azithromycin in $11.87 \%$, tretinoin in $11.42 \%$, benzoyl peroxide in $4.95 \%$, and adapalene in $4.64 \% .{ }^{9}$ In Sharma et al study, among the topical monotherapy, benzoyl peroxide $5 \%$ was given $30 \%$, adapalene $0.05 \%$ in $11.76 \%$, clindamycin $1 \%$ in $15.29 \%$, benzoyl peroxide $2.5 \%$ in $12.35 \%$, and ketoconazole in $12.35 \%$, while among those with topical polytherapy, clindamycin phosphate $1 \%$, aloe vera $10 \%$, liquid paraffin $7 \%$, white soft paraffin 5\% was prescribed in $18.24 \% .{ }^{17}$ In Gupta et al study, among topical agents, clindamycin was most common in $79.78 \%$, followed by adapalene in $63.93 \%$, tretinoin in $28.4 \%$, ketoconazole in $11.5 \%$, and mometasone in $7.65 \% .{ }^{10}$ In Chandani et al study, out of the prescribed topical drugs, clindamycin phosphate was most commonly prescribed $(26.83 \%)$, followed by salicylic acid facewash $(24.26 \%)$, adapalene $(13.24 \%)$, benzoyl peroxide $(8.09 \%)$, isotretinoin $(6.99 \%)$ and nicotinamide $(6.62 \%) .{ }^{11}$ In Pooja et al study, among the 514 drugs prescribed for topical use, benzoyl peroxide was most common in $19.46 \%$, followed by tretinoin + clindamycin in $17.12 \%$, facewash in $15.56 \%$, tretinoin in $12.45 \%$, clindamycin in $10.51 \%$, and adapalene + benzoyl peroxide in $7.78 \% .^{12}$

In current study, among the drugs prescribed by oral route, doxycycline was most common $(63.36 \%)$, followed by isotretinoin $(18.81 \%)$, doxycycline + lactobacillus (10.89\%), and azithromycin (6.93\%). In Giri et al study, systemic drugs as monotherapy were prescribed, with azithromycin in $30 \%$ and levocetrizine in $12.5 \%$, polytherapy comprising of doxycycline and ranitidine were prescribed in 57.5\% ${ }^{16}$ Among oral drugs in Kumar et al study, antibiotics constituted $43.31 \%$, multivitamins were $27.81 \%$, antifungals were prescribed in $14.64 \%$, anithistaminics were $8.06 \%$ and miscellaneous drugs constituted $6.15 \%$. Among antibiotics, azithromycin was most commonly prescribed $(85.78 \%)$, among antifungals, fluconazole was common (63.76\%), among antihistaminics, cetirizine was common $(58.63 \%){ }^{13}$ Among oral drugs in Patro et al study, isotretinoin was commonly prescribed constituting $68.1 \%$ of all oral drugs, followed by $31.9 \%$ antibiotics, of which doxycycline was most common (54.18\%), followed by azithromycin $(38.73 \%)$, minocycline $(5.45 \%)$, and clarithromycin (1.64\%). ${ }^{8}$ In Agarwal et al study, among the oral drugs with monotherapy, vitamin A was most common in $20 \%$, followed by azithromycin in $7 \%$, doxycycline in $5 \%$ and vitamin $\mathrm{C}$ in $4 \%$, while among those with polytherapy, vitamin $\mathrm{A}+$ azithromycin was used in $23 \%$, vitamin $\mathrm{A}+$ vitamin $\mathrm{C}$ in $18 \%$, vitamin $\mathrm{A}+$ vitamin $\mathrm{C}+$ azithromycin in $9 \%$ were common, with overall, vitamin being the most commonly prescribed oral medication and azithromycin being the most common antibiotic prescribed. ${ }^{14}$ In Kamerkar et al study, among the orally administered drugs, azithromycin was most common in $62.5 \%$ patients, followed by isotretinoin in $12.5 \% .^{15}$ In Nandini et al study, among oral medications, azithromycin was most common in $15.53 \%$, followed by doxycycline in $11.42 \%$, nadifloxacin $7.31 \%$, and retinoids in $5.94 \% .{ }^{9}$ In Sharma et al study, among those with systemic monotherapy, azithromycin $500 \mathrm{mg}$ was prescribed in $28.82 \%$, levocetrizine $5 \mathrm{mg}$ in $13.53 \%$, while among those with systemic polytherapy, doxycycline $100 \mathrm{mg}$ and ranitidine $150 \mathrm{mg}$ was prescribed in $57.65 \%$ patients. ${ }^{17}$ In Gupta et al study, among the oral drugs, azithromycin was most common in $41.53 \%$, followed by doxycycline in $28.96 \%$, isotretinoin in $15.3 \%$, minocycline in $14.75 \%$, and fluconazole in $15.57 \% .^{10}$ Among the systemically 
administered drugs in Chandani et al study, azithromycin was most common (33.33\%), followed by doxycycline $(26.49 \%)$, and isotretinoin $(20.51 \%) .{ }^{11}$ In Pooja et al study, among the 98 drugs used by systemic route, doxycycline was most common in $55.1 \%$, followed by azithromycin in $34.7 \%$, isotretinoin in $6.12 \%$, and erythromycin in $4.08 \% .^{12}$

Published literature revealed that majority of studies had described the prescription pattern of drugs altogether for acne patients, irrespective of the severity of the disease. The investigators in the current study are of the view that the treatment of the acne patients is guided according to the standard guidelines which state different mode of treatment approaches depending on the severity of the acne disease, and thus, severity of acne significantly affects the prescription of acne vulgaris patients. In the patients with mild acne, salicylic acid + glycolic acid facewash was most commonly prescribed in $92 \%$ patients, followed by adapalene + clindamycin in $77.3 \%$ followed and clindamycin + nicotinamide in $61.4 \%$. In mild acne, among the oral drugs, only doxycycline was prescribed in $34.1 \%$. Comparatively, in patients with moderate acne, adapalene + clindamycin was prescribed in all patients, followed by foaming facewash in $62.7 \%$, and clindamycin in $58.8 \%$. Among the oral medications, doxycycline was used in $62.7 \%$, while combination of doxycycline + lactobacillus was used in $21.6 \%$, contributing to a total of $84.3 \%$ patients of moderate acne being prescribed with doxycycline as an antibiotic. In severe acne patients, among topical medications, adapalene + clindamycin, clindamycin, and foaming face wash were used in $90.5 \%$ patients, while among oral medications; isotretinoin was given in $90.5 \%$ patients. Thus, a specific prescription pattern in a certain severity of acne disease indicating the most preferred treatment. International guidelines were followed in our study.

Acne vulgaris significantly affects the quality of life as demonstrated in multiple studies. ${ }^{18-20}$ The mean CADI score decreased at subsequent visits indicating that the quality of life improved with treatment of acne. This was mostly affected by the improvement in severity of acne due to effect of anti-acne medications. Thus, though polypharmacy may be a common practice in anti-acne medications, the following of AAD guidelines in treatment of acne, benefit the patient in terms of therapeutic benefit and QoL.

\section{CONCLUSION}

Multidrug therapy is a common practice in acne vulgaris patients. Topical medications contribute to about $80 \%$ of anti-acne medications in practice. Anti-acne medications lead to improvement in severity of acne and quality of life in patients.

\section{Funding: No funding sources}

Conflict of interest: None declared
Ethical approval: The study was approved by the Institutional Ethics Committee (2017/03/SC/32)

\section{REFERENCES}

1. Zaenglein AL, Pathy AL, Schlosser BJ, Alikhan A, Baldwin HE, Berson DS, et al. Guidelines of care for the management of acne vulgaris. J Am Acad Dermatol. 2016;74(5):945-73.e33.

2. Lunde PK, Baksas I. The methodology of drug utilization studies. In: Bergman U, Grimson A, Westerholm B, editors. Studies in Drug Utilization. WHO Regional Office for Europe. 1979;8:17-28.

3. Bijoy KP, Vidyadhar RS, Palak P, Chintan SP, Atmaram PP. Drug prescribing and economic analysis for skin diseases in dermatology OPD of an Indian tertiary care teaching hospital: a periodic audit. Indian J Pharm Pract. 2012;5(1):28-33.

4. Gupta N, Sharma D, Garg S, Bhargava V. Auditing of prescriptions to study utilization of antimicrobials in a tertiary hospital. Indian $\mathbf{J}$ Pharmacol. 1997;29(6):411-5.

5. Adityan B, Kumari R, Thappa DM. Scoring systems in acne vulgaris. Indian J Dermatol Venereol Leprol. 2009;75(3):323-6.

6. Department of Dermatology- Cardiff University. Cardiff Acne Disability Index (CADI). Available from: https://www.cardiff.ac.uk/medicine/resources/ quality-of-life-questionnaires/cardiff-acne-disabilityindex. Accessed on 12 March 2019.

7. Gupta A, Sharma Y, Dash K, Verma S. Cultural adaptation of the Cardiff Acne Disability Index to a Hindi speaking population: a pilot study. Indian $\mathbf{J}$ Dermatol. 2015;60(4):419.

8. Patro N, Jena M, Panda M, Dash M. A study on the prescribing pattern of drugs for acne in a tertiary care teaching hospital in Odisha. J Clin Diagn Res. 2015;9(3):WC04-6.

9. Nandini T, Kumbar SK, Padmanabha TS, Krishna P, Narendra G. A prospective study of pattern of prescription for acne vulgaris in a tertiary care hospital: an observational study. Int J Basic Clin Pharmacol. 2016;5:2357-61.

10. Gupta A, Dhande PP. Drug utilizing pattern for acne vulgaris in a tertiary care teaching hospital. J Basic Clin Pharm. 2017;8:230-4.

11. Chandani K, Raval R, Rana D, Malhotra S. Study of drug use pattern and analysis of quality of life in patients of acne attending the dermatology OPD. Nat J Integr Res Med. 2018;9(1):108-16.

12. Pooja M, Holla R, Girisha BS, Puneeth A. A study of prescription pattern in the drug therapy of acne vulgaris at a tertiary care hospital in Mangalore, India. Int J Basic Clin Pharmacol. 2018;7:80-6.

13. Kumar S, Dutta S, Beg M, Mehta A, Anjoom M, Sindhu S. Drug utilization pattern in acne vulgaris in skin outpatients department of a tertiary care teaching hospital at Dehradun, Uttarakhand. Int J Med Sci Public Health. 2014;3(7):855. 
14. Agarwal S, Pillai A, Singh AP, Pareek R, Bhuptani N. Drug utilization study of medications used for acne vulgaris in a tertiary care hospital. Eur J Biomed Pharm Sci. 2016;3(11):311-5.

15. Kamerkar SA. Prescription pattern and the cost analysis of tinea and acne patients in the dermatology department of a tertiary care teaching hospital. RA J Appl Res. 2016;2(2):416-23.

16. Giri VP, Kanodia S, Giri OP, Haque A. Prescription audit of acne vulgaris in skin outpatient department of a tertiary care teaching hospital. J Evol Med Dent Sci. 2014;3(52):12179-83.

17. Sharma V, Bajpai A. Study of prescription pattern for acne vulgaris in dermatology OPD in a tertiary care teaching hospital. Int $\mathbf{J}$ Med Res Prof. 2016;2(2):316-9.

18. Ghaderi R, Saadatjoo A, Ghaderi F. Evaluating of life quality in patients with acne vulgaris using generic and specific questionnaires. Dermatol Res Pract. 2013;2013:108624.

19. Abdel-Hafez K, Mahran AM, Hofny ERM, Mohammed KA, Darweesh AM, Aal AA. The impact of acne vulgaris on the quality of life and psychologic status in patients from Upper Egypt. Int J Dermatol. 2009;48(3):280-5.

20. Hazarika N, Rajaprabha RK. Assessment of life quality index among patients with acne vulgaris in a suburban population. Indian $\mathrm{J}$ Dermatol. 2016;61:163-8.

Cite this article as: Sane RM, Shahani SR, Sane AM, Muppalla B. An observational study to assess the drug prescription pattern and quality of life of acne vulgaris patients in a tertiary care center in India. Int J Basic Clin Pharmacol 2020;9:1364-70. 